\title{
The Exploration and Promotion of the Revitalization Strategy of Rural Areas in Hainan Province
}

\author{
Lulu Sun ${ }^{1}$ \\ ${ }^{1}$ Haikou University of Economics, Haikou, Hainan, 571127
}

\begin{abstract}
Keywords: revitalization strategy; rural areas; Hainan Province
\end{abstract}
\begin{abstract}
The rural revitalization strategy is a major strategic concept to build a modern power in the new era. This paper analyzes the role of the rural rejuvenation strategy in resolving the main contradictions of China's social development, with four key points, four major paths, and four misunderstandings of the rural rejuvenation strategy. It is recommended to focus on strategic key points, follow the roadmap with the least resistance to strategy implementation, follow the four major paths, avoid potential risks, and thoroughly implement the rural rejuvenation strategy to create a new pattern of urban-rural integration development that meets the requirements of the new era.
\end{abstract}

\section{Introduction}

The party's report on the Nineteenth Congress placed the issue of solving the "three rural issues" in a crucial position. For the first time, it proposed to "implement the strategy for rejuvenating villages" as the six major tasks of implementing new development concepts and building a modern economic system. First, it has proposed new deployments and new requirements for implementing this strategy. The Provincial Economic Work Conference held today has deployed the next step in implementing the spirit of the Nineteenth National Congress and implementing the strategy for the promotion of rural development. Relevant officials from some cities and counties expressed that they must conscientiously implement the spirit of the 19th National Congress and the spirit of the Provincial Party Committee Economic Work Conference, implement the strategy of village rejuvenation in a solid manner, and promote the construction of the "100 Thousand Villages in Thousand Villages” project in beautiful Hainan, making the construction of villages and towns in Hainan a suitable condition. The rural tourism destination where the industry is suitable for leisure and tourism should gradually build Hainan into an open island, a green island, an island of civilization, and an island of harmony with a beautiful ecological environment, unique cultural charm, and harmonious social civilization [1].

The unbalanced development of urban and rural areas has the reason of economic and social self-regulation. This is the inevitable outcome of China's economic and social development at a certain stage. There are also institutional reasons. The urban and rural household registration system further intensifies or solidifies this imbalance in different stages. To sum up, the uneven development of urban and rural areas is manifested in three aspects. First, the economic and social development in urban and rural areas is uneven. In the past development of our country, the key areas of economic and social development are cities and towns, and the key industries are non-agricultural industries; the economic and social development in rural areas is often overlooked, and agriculture is often a weak industry in industrial development. This has led to the transfer of funds, technology, and human resources to urban and non-agricultural industries. The social and economic development in rural areas has been plunged into poverty, absurdity, disorder, and backwardness. This unbalanced development situation needs to be improved urgently. The strategy of rejuvenating the countryside is an inevitable choice to meet the requirements of the development of the times. Second, the urban and rural infrastructure construction and the provision of public services are not balanced. Under the influence of many factors, China's urban and rural infrastructure construction and the provision of public services are seriously out of balance. Among them, the core factor is the institutional factors, the allocation of resources in the "separation of 
urban and rural areas" and the asymmetrical financial power system between governments at all levels. In general, in the past, our country's urban infrastructure construction and public product supply were mainly "hands-packed" by the government, while rural areas were mainly "breaded" by farmers themselves, which led to the over-speed development of urban infrastructure and public utilities, and the backward development of rural areas. The supply of facilities and public goods is seriously insufficient, and the gap between urban and rural areas is continuously widening. Therefore, the level of infrastructure and public services enjoyed by per capita peasants is much lower than that of urban residents. As a result, "the supply of infrastructure and public services is weak - the mass transfer of highly qualified agricultural populations - the scale effect of investment has further declined - infrastructure and public The vicious circle of continued weakness and deterioration in service. Breaking this vicious circle urgently needs to vigorously implement the strategy of rural rejuvenation [2].

\section{The Level and Precision of Hainan Rural Development}

Hainan's rural areas have significant multi-level differences. This is mainly reflected in the differences in geographical location, natural resource endowments, economic development level, and village governance capacity. From the poverty level, it can be divided into four levels: poor villages, well-off villages, rich countryside and developed villages. From a spatial perspective, there are suburban villages, middle-level villages, and remote villages. From the organizational form, there are the original slash-and-burn, the traditional small-scale production, professional farmers small-scale production, farming enterprise production, foreign investment in production, "net", "intelligent" modern agriculture and other levels, and so on. The complexity of the differences in levels determines that "one size fits all” policy measures cannot promote the implementation, implementation, and reduction of the strategy for the promotion of rural development. Fu Guohua proposed a hierarchical management theory, referring to the realization of management's intended purpose under specific environmental conditions, to fine-grained the development level of management objects, and to identify the efficient integration methods and paths of input elements and management resources according to different levels of needs. Management adaptation reduces the management inefficiencies and resource waste caused by dislocation management, maximizes output, and optimizes management effectiveness. Hierarchical management is the theoretical basis for precision policy. Local governments should make accurate decisions and should combine local conditions with different levels of analysis to formulate a localized "village rejuvenation strategy." This is the specific requirement for the implementation of the country's "rejuvenation strategy for rural areas," and it is also the fundamental issue for breaking the development challenges [3].

\section{Implementation of Rural Revitalization Strategy in Hainan}

First, the people of the province must conscientiously study and comprehend the spirit and content essence of General Secretary Xi Jinping's report in the Party's Nineteenth Congress on "Implementing the Strategy for Revitalizing the Country". The second is to unify the integration and preparation of the unified planning and task decomposition of the rural rejuvenation strategy in Hainan. In planning, special emphasis should be placed on accelerating the promotion of rural rejuvenation strategies at different levels. Scientifically identify the development level of Hainan's rural areas, implement accurate policies, and achieve a comprehensive upgrade of rural development at all levels. From the analysis of the development and accumulation, it is necessary to accurately set goals and break through layers. The rural revitalization strategy is to achieve poverty-stricken villages that escape poverty and lead a well-off society, develop relatively well-off rural areas and become wealthy, develop rich and affluent rural areas, and develop well-developed rural areas. From the spatial stratification of rural areas, the strategy of rural revitalization of suburban villages, the strategy of revitalizing villages in the middle zone, the strategy of revitalizing rural villages in remote areas, and the strategy of urban and rural development in cities can be implemented. From the perspective of the development of rural agriculture, we can formulate 
strategies for the revitalization of traditional agriculture and rural areas and strategies for revitalizing modern agriculture and rural areas, in particular the strategy of "village + information" rejuvenation, the strategy of "village + intelligence" rejuvenation, and the high-end development of ecological villages. There are mainly shortcomings and weaknesses in the development of rural areas in Hainan [4]. First, modern ideology needs to be supplemented. To develop new ideas, new technologies, and new revolutions, and to realize the development goals of the revitalization of the countryside, we need to think about and implement the work from a higher and longer-term perspective. The second is the loss of rural talents. There are too few talented people who know and farm, and many jobs cannot be carried out at the grassroots level. Third, the construction of the agricultural modernization system is incomplete and inadequate. The modernization of science and technology in rural areas is weak, and it faces low efficiency and serious soil pollution. Fourth, there is a serious shortage of "nutrition" in rural development. The industry is absent, and farmers have a single income channel. The fifth is that "village + information" "village + intelligence" is still in its infancy. Sixth, "village + ecological livable" and the realization of ecological civilization are still in the process of exploration. To achieve ecological livability, we need to further innovate production development methods.

Hainan's rural industry is mainly characterized by high-efficiency tropical agriculture, and it should follow the spirit of the Provincial Party Committee and the provincial government to "build a trump card for tropical characteristics and high-efficiency agriculture.” First, we must speed up the transformation of agricultural development methods and complete the transformation and upgrading of traditional agriculture to standardization, branding, and industrialization. From the simple pursuit of production to the pursuit of quality change, from extensive management to fine business transformation, from non-sustainable development to sustainable development changes, from low-end supply to high-end supply four changes. Second, we must promote the optimization of agricultural structure, extend the agricultural industry chain, and improve the level of deep processing of agricultural products. Third, we must improve the quality of agricultural products, strengthen the building of agricultural brands, and promote the transformation of tropical agriculture in Hainan to high quality and high efficiency. The fourth is to improve the agricultural socialization service system, and realize the organic convergence of small farmers' decentralized management and modern agricultural intensive development. Fifth, we must make full use of the advantages of the legislative power of the Hainan Special Economic Zone to steadily promote the reform of the "three powers" of rural land and the transfer of the right to operate. Sixth, we must give play to the role of agricultural science and technology, and in particular, play a role in agricultural research institutes and universities in scientific research, agricultural technology promotion, and technical training [5].

Hainan is an ecological province with the best ecological environment and abundant natural resources in the country. It is recommended to make full use of the advantages and characteristics of "the best ecological environment in the country", "tropical” and "coastal water", develop ecological livable villages, expand the potential of ecological demand, and highlight the attractiveness of Hainan's rural areas. On the one hand, as soon as possible research projects, accelerate the establishment of relevant indicators of ecological livability system, do a full study of ecological civilization related policies, the theory first; on the other hand, as soon as possible to select, design, build ecological livable village demonstration sites, point to surface, in the country to form Certain influence will be exerted to promote green and low-carbon development. It will strive to create an excellent practice example of "Beautiful China" in Hainan.

Good rural civilization is the embodiment of the spirit and quality of rural development. To maintain a good rural style, we should do the following: First, build a new culture in the new era, vigorously tap and develop Hainan's rural culture, give new meaning to the times, reshape the cultural self-confidence of Hainan villages, and make culture a strong support for rural civilization. . The second is that the new era attracts Xinxiangxian, connects with the local conditions, and encourages outstanding Hainanese talents to return to the world with Qiongliao. Based on an excellent ecological environment, we will attract talented people and social elites from all over the 
country to provide pensions in rural Hainan. The third is to set a new benchmark for the new era, and to "exemplify benchmarks and demonstrations" with outstanding grass-roots cadres, moral models, and good-natured people. The fourth is the new era, catching new models, selecting typical models from the masses, and relying on the masses to push Typical, establish a batch of advanced features of the township civilization with the characteristics of the new era.

The scientific and effective mode of rural governance is an important guarantee for the comprehensive promotion of the strategy of rural revitalization. To achieve rural revitalization, it is necessary to focus on strengthening rural self-government, the rule of law, and moral construction. First, we must improve the autonomy mechanism for rural governance, consult public opinion before major rural policy decisions, pay attention to promoting democracy, centralizing people's wisdom, reflecting public opinion, ensuring people's right to participate in, participating in decision-making, and supervising the major issues at the village level, ensuring the public nature of decision-making, and making public Sex and science. Second, we must strengthen the rule of law in rural governance, clarify the main responsibility for the rule of law, establish a rule-by-law system for rural governance, strengthen publicity and education, and give full play to the role of village rules and regulations in rural governance. Third, we must strengthen the rule of the rule of the rule of rural governance, use moral construction as an opportunity, give full play to the effectiveness of moral education, and govern the village by virtue.

\section{Conclusion}

The implementation of the rural revitalization strategy is an important starting point and an inevitable choice for solving the major contradictions faced by China's economic and social development in the new era. Proposing, formulating, and implementing a rural revitalization strategy will play an important role in resolving major social conflicts in our country. In this period of strategic opportunities, we must seize the four key strategic points, follow the four major strategic paths, evade potential misunderstandings, implement the Party Central Committee's great strategic concept of rural revitalization, and create a new pattern of urban-rural integration and development. Must adhere to the "human urbanization" as the core, implementation of urbanization and rural rejuvenation two-wheel drive urban-rural integration development strategy to promote urban and rural synchronization, coordination, harmony, integration and equal development.

\section{References}

[1] Chen Wensheng. How to Understand the "Country Revitalization Strategy" [J]. Rural Work News, 2017, (21): 18 22.

[2] Liu Heguang, Qin Fu. Thoughts on Perfecting China's Agricultural Subsidy Policy [J]. Economic Research Reference, 2015, (48): 212 214.

[3] Li Qiang. The key is the urbanization of people - the study and implementation of the important speech of General Secretary Xi Jinping at the Central Economic Work Conference [J]. 2015, (3): 76 81.

[4] Li Wei. The key to rural revitalization plan is to seize people, land and money [J]. Rural Work News, 2017, (21): 48 51.

[5] Ye Xingqing. Leading the modernization of agriculture and rural areas with the strategy of rural rejuvenation [J]. China Development Watch, 2017, (21): 121 122. 